\title{
The Effects of Recycled Tire Rubbers and Steel Fibers on the Performance of Self-compacting Alkali Activated Concrete
} \author{
Mehmet Eren Gülşan ${ }^{1}$ \\ ${ }^{1}$ Department of Civil Engineering, Gaziantep University, 27310 Gaziantep, Turkey \\ ${ }^{2}$ Akre Technical Institute, Duhok Polytechnic University, 42001 Duhok, Iraq \\ ${ }^{3}$ Architechture Department, Nawroz University, 42001 Duhok, Iraq \\ ${ }^{4}$ Department of Civil Engineering, Istanbul Gelisim University, 34315 Istanbul, Turkey \\ * Corresponding author, e-mail: altayeren@gantep.edu.tr
}

Necip Altay Eren ${ }^{1 *}$, Radhwan Alzeebaree $^{2,3}$, Abdulkadir Çevik$^{1}$, Anıl Niş$^{4}$, Alaa Mohammedameen $^{2,3}$,

Received: 29 November 2020, Accepted: 27 March 2021, Published online: 09 April 2021

\begin{abstract}
In this study, the effects of recycled tire rubbers (RTR) and steel fiber (SF) on the fresh and hardened state properties of the selfcompacted alkali activated concrete (SCAAC) were investigated. The ground granulated blast furnace slag, $1 \%$ hooked-end SF, and two types of RTR were utilized. The crumb rubbers (CR) and tire rubber chips (TCR) were used as a substation to natural aggregates at substation levels of $10 \%$ and $15 \%$. The fresh state performances were evaluated by T50 value, slump flow, V-funnel, and L-Box tests, while mechanical performances were assessed through compressive, flexural, and splitting tensile strength tests. Also, detailed crack and microstructural analyses were conducted. The RTR adversely affected the fresh state properties, which reduced more with SF inclusions. Among the RTR, the TR specimens exhibited lower fresh state performance than the CR specimens. Similar mechanical strengths were obtained on the TR and CR specimens under the same replacement ratios. However, TR specimens exhibited higher deformation capacities than the CR specimens, when SF was utilized. The SCAAC specimens with 1 \% SF and $15 \%$ RTR showed more and wider flexural cracks, higher mechanical strength, and deformation capacity, which can be utilized in structural applications, particularly in high seismic zones.
\end{abstract}

Keywords

self-compacting concrete, alkali activated concrete, recycled tire chips, crumb rubber, steel fiber

\section{Introduction}

Nowadays, a serious environmental problem emerges in the world due to the massive quantity of waste tire materials. The billions of tires in the world are buried and/or throw away to the global environment, which results in an obvious environmental threat into the world, especially in the regions where huge amounts of tires are produced. The oil that includes toxic and soluble components [1] emerges during the burning procedure of the waste tires, which pollutes the soil and water [2]. Tire landfilling also considered to be a significant ecological threat since waste tire disposal areas reduced biodiversity due to the toxic and soluble components of the tires [3]. The less available landfill area, the increased cost of accumulation, and the transportation of waste tires are also considered to be the main problem for waste tire disposal. Researchers expected that the number of waste tires will increase up to about 5000 million in 2030 if the number of motor vehicles increased to 1200 million [3], which will cause serious environmental pollution. It was reported that the vehicle number in China was 240 million, and the cumulative automobile tire number was 648 million, and approximately 14.58 million tons of waste tires were produced in 2018 [4]. Therefore, it becomes crucial importance of recycling such a big number of waste tires for possible utilization in the construction industry, which becomes one of the best solutions for both economy and cleaner environments. Also, the utilization of recycled rubbers in construction industries can decrease the dependency on natural aggregates, resulting in more sustainable constructions [5].

The utilization of tire chips and crumb rubbers as recycled rubbers in concrete takes great attention to improve low deformation capacity, poor tensile strength, and energy 
absorption capacity [6]. However, the tire rubber substitution ratio should be lower than $20 \%$ to prevent a detrimental effect on the mechanical strength of the rubberized concrete [7]. The slump of the rubberized concrete decreased with an increase in the rubber content [8]. Another problem is the early cracking due to the lack of an adequate bond between rubbers and concrete, hence it has been limited to non-structural applications [5].

Recently, eco-friendly cleaner geopolymer or alkali activated concrete has been preferred instead of OPC concrete due to less energy requirement and environmental pollution [9]. The alkali activated concrete exhibited superior mechanical and durability performance for structural utilization [10-12]. In addition, self-compacted concrete is widely used for the structural elements that required congested steel rebars and the essential properties of the SCC are passing ability and flowability without bleeding and segregation [13]. Generally, industrial by-product materials like ground granulated blast furnace slag, fly ash, and silica fume with a binder content of $500-600 \mathrm{~kg} / \mathrm{m}^{3}$ are utilized to enhance flowability, passing ability, mechanical strength and to decrease the cost of the SCC [14]. Subsequently, self-compacting alkali activated concretes (SCAAC) have drawn great attention for structural utilization to reduce environmental hazards of OPC production $[15,16]$; Although there are many studies regarding the self-compacting concrete with OPC, there are limited studies about the SCAAC, especially reinforced with steel fibers and recycling tyre rubbers.

Similar to OPC concrete, the SCAAC performs brittle behavior under reversed loadings. In general, steel fibers are utilized to enhance splitting tensile strength, flexural strength, post-cracking behavior, ductility, and toughness of the concrete [17]. The structural performance was mainly influenced by the steel fiber volume, and $1 \%$ steel fiber content was considered to be optimum steel fiber volume for the sake of economy [18].

Although there are several studies regarding OPC based SCC incorporating waste tires, very few studies have been conducted on the flowability, passing ability, and mechanical properties of self-compacted alkali activated concretes with recycled rubber tires and steel fibers. Therefore, the aim of this research is to investigate the combined use of recycled tire rubbers and steel fibers on the flowability, passing ability, and mechanical properties of SCAAC samples cured under the ambient environment. In addition, detailed crack and SEM analyses of fibrous and rubberized SCAAC specimens were executed to find out the possible utilization of recycled tire rubber based SCAAC specimens in the structural concrete elements.

\section{Experimental procedure \\ 2.1 Materials}

The ground granulated blast furnace slag with a specific surface area of $418 \mathrm{~m}^{2} / \mathrm{kg}$ and a specific gravity of $2.70 \mathrm{~g} / \mathrm{cm}^{3}$ was utilized as binder materials for the slag based self-compacted alkali activated concrete (SCAAC). Slag has $\mathrm{CaO}$, $\mathrm{SiO}_{2}, \mathrm{Al}_{2} \mathrm{O}_{3}, \mathrm{Fe}_{2} \mathrm{O}_{3}$, and $\mathrm{MgO}$ contents of $34.12 \%, 36.40 \%$, $11.39 \%, 1.69 \%$, and $10.30 \%$, respectively. The crushed limestone coarse and fine aggregates were used in the SCAAC specimens. The recycled tire rubber (RTR) materials; tire rubber chips (TR) as a coarse rubber aggregate, coarse crumb rubber, and fine crumb rubber (CR) as fine aggregates, were utilized in the production of SCAAC as shown in Fig. 1. Table 1 illustrates the sieve analysis of the RTR materials. Also, $1 \%$ of steel fibers (SF) were introduced to some of the rubberized SCAAC specimens to investigate the flowability, passing ability, and hardened state properties of SCAAC specimens. For this aim, nine rubberized SCAAC specimens with/out SF were produced, and TR and CR were replaced with $10 \%$ and $15 \%$ of coarse and fine aggregates, respectively. For the $10 \%$ or $15 \% \mathrm{CR}$ replacements, coarse and fine $\mathrm{CR}$ were replaced with equal ratios of $5 \%$ and $5 \%$, or $7.5 \%$ and $7.5 \%$, respectively.

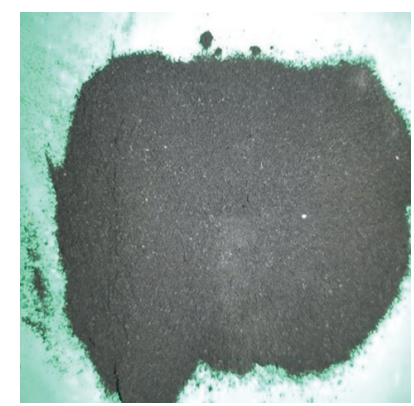

(a)

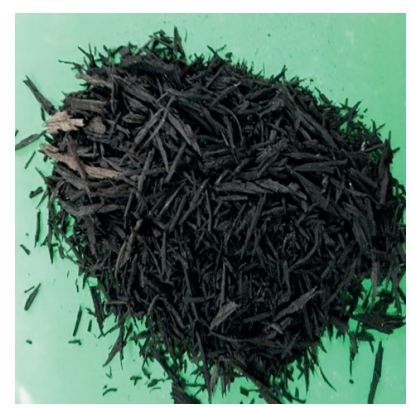

(c)

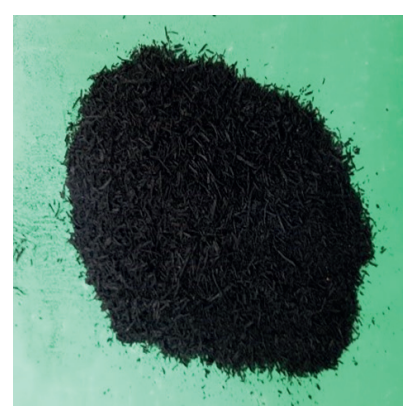

(b)

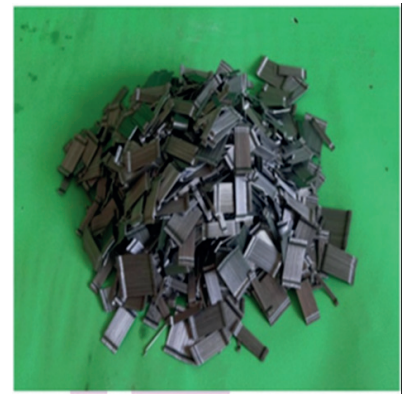

(d)
Fig. 1 The utilized materials in the production of SCAAC 
Table 1 Sieve analysis of the recycled tire rubbers

\begin{tabular}{lcccccc}
\hline Sieve Size (mm)/ & 0.25 & 0.5 & 1 & 2 & 4 & 8 \\
Material passed (\%) & & & & & & \\
\hline Coarse Crumb Rubber & 12.2 & 21.8 & 33.5 & 81.7 & 100 & 100 \\
Fine Crumb Rubber & 11.1 & 47.4 & 86.3 & 100 & 100 & 100 \\
Tire Crumb Rubber & 5.3 & 9.6 & 24.6 & 53.8 & 89.6 & 100 \\
\hline
\end{tabular}

A polycarboxylate ether based superplasticizer, Master Glenium 51, was used to achieve the requirements of the SCC by the related standards.

The waste tires were taken from the utilized truck tires discarded after a $2^{\text {nd }}$ recapitulating. The TR and CR materials were prepared by mechanical shredding and the gradation of crumb rubbers was determined according to ASTM C136 standard [19]. The TR with a specific gravity of 1.02, and coarse and fine CR with specific gravities of 0.83 and 0.48 , and hooked-end SF with a length of $30 \mathrm{~mm}$, a diameter of $0.75 \mathrm{~mm}$, an aspect ratio of 40 , and a volume ratio of 1 were utilized in the production of rubberized SCAAC specimens. The sodium silicate $\left(\mathrm{SiO}_{2}: 29.4\right.$, water: $55.9 \%$, and $\mathrm{Na}_{2} \mathrm{O}: 13.7 \%$, by mass) and sodium hydroxide (97\%-98\% purity) with a sodium silicate to hydroxide ratio of 2.5 were utilized as an alkali activator. The sodium hydroxide molarity was selected as $12 \mathrm{M}$ since $12 \mathrm{M} \mathrm{NaOH}$ was found to be the optimum concentration amount for the superior mechanical strength of SCC mixes [20].

\subsection{Mix design}

For the preparation of the nine different SCAAC specimens, two series were produced with $100 \%$ ground granulated blast furnace slag without steel fibers (SF0) and with $1 \% \mathrm{SF}$ (SF1) incorporations. Table 2 shows the material amounts of the rubberized SCAAC specimens with/ out steel fibers, and the alkali activator/binder ratio was kept constant for all mixes. The CR, TR, and SF refer to crumb rubber, tire rubber chip, and steel fiber, respectively. The CR and TR were used as a substitution to natural aggregates with $10 \%$ and $15 \%$ as shown in Table 1 . For the $10 \%$ or $15 \%$ CR substitutions as fine aggregates, coarse and fine CR were used at equal substitution levels of $5 \%$ and $5 \%$, or $7.5 \%$ and $7.5 \%$, respectively. For the economic alkali activated concrete production, the sodium silicate/sodium hydroxide ratio should be in the range of 1.5 to 2.5 [21], thus sodium silicate to sodium hydroxide ratio of 2.5 was selected for the production of specimens.

\subsection{The fresh properties of rubberized SCAAC mixes}

The flowability and viscosity of rubberized SCAAC mixes were measured by slump flow and V-funnel tests, whilst the passing ability was measured via the L-Box test. During the flowability tests, slump flow along both $\mathrm{x}$ and $\mathrm{y}$ directions were measured and $t_{50}$ flow time was recorded when the slump flow reaches $50 \mathrm{~cm}$. The $\mathrm{V}$-funnel section was filled with the rubberized SCAAC mixes and the discharge period from the V-Funnel section was noted. The passing ability requirement of the rubberized SCAAC mixes was also studied using L-box test-setup, and the passing ability through tight openings $(41 \pm 1 \mathrm{~mm})$ was measured by dividing the concrete heights of lateral L-Box part to vertical L-Box part (PL value).

\subsection{Curing method of the rubberized SCAAC samples}

After the casting procedure, required compaction was applied to the specimens. Then, the upper surface of the rubberized samples was coated with plastic sheets to eliminate the alkali solution evaporation. The produced rubberized samples were demolded after $24 \mathrm{~h}$ later and then kept in the laboratory medium at $23 \pm 2 \circ \mathrm{C}$ at the ages of 28 days. In the previous investigation, it was reported that slag-based alkali activated concretes can be utilized in

Table 2 Material ingredients of SCAAC mixes for $1 \mathrm{~m}^{3}$

\begin{tabular}{|c|c|c|c|c|c|c|c|c|}
\hline Mixture & $\begin{array}{c}\mathrm{Na}_{2} \mathrm{SiO}_{3}+\mathrm{NaOH} \\
\mathrm{kg} / \mathrm{m}^{3}\end{array}$ & $\begin{array}{c}\text { Slag } \\
\mathrm{kg} / \mathrm{m}^{3}\end{array}$ & $\begin{array}{c}\text { FCR } \\
\mathrm{kg} / \mathrm{m}^{3}\end{array}$ & $\begin{array}{l}\mathrm{CCR} \\
\mathrm{kg} / \mathrm{m}^{3}\end{array}$ & $\begin{array}{c}\mathrm{TR} \\
\mathrm{kg} / \mathrm{m}^{3}\end{array}$ & $\begin{array}{c}\mathrm{SF} \\
\mathrm{kg} / \mathrm{m}^{3}\end{array}$ & $\begin{array}{c}\text { Fine Agg. } \\
\mathrm{kg} / \mathrm{m}^{3}\end{array}$ & $\begin{array}{c}\text { Coarse Agg. } \\
\mathrm{kg} / \mathrm{m}^{3}\end{array}$ \\
\hline SF0CR0TR0 & 250 & 500 & 0 & 0 & 0 & 0 & 860.07 & 738.12 \\
\hline SF0CR10 & 250 & 500 & 7.95 & 10.65 & 0 & 0 & 700.80 & 738.12 \\
\hline SF0CR15 & 250 & 500 & 11.9 & 15.98 & 0 & 0 & 621.16 & 738.12 \\
\hline SF0TR10 & 250 & 500 & 0 & 0 & 30.9 & 0 & 860.07 & 577.66 \\
\hline SF0TR15 & 250 & 500 & 0 & 0 & 46.4 & 0 & 860.07 & 497.43 \\
\hline SF1CR10 & 250 & 500 & 7.95 & 10.65 & 0 & 78.40 & 700.80 & 738.12 \\
\hline SF1CR15 & 250 & 500 & 11.9 & 15.98 & 0 & 78.40 & 621.16 & 738.12 \\
\hline SF1TR10 & 250 & 500 & 0 & 0 & 30.9 & 78.40 & 860.07 & 577.66 \\
\hline SF1TR15 & 250 & 500 & 0 & 0 & 46.3 & 78.40 & 860.07 & 497.43 \\
\hline
\end{tabular}


structural applications without oven-curing or water curing [22]. Therefore, oven-curing or water curing was not applied to the specimens. The typical three samples were cast to achieve average values for each experiment results.

\subsection{The mechanical strength performance}

\subsubsection{Compressive strength tests}

The compressive strength tests of the rubberized SCAAC specimens with/out SF were carried out on $100 \times 100 \times$ $100 \mathrm{~mm}$ cube specimens according to ASTM C39 standard [23]. The influences of the TR, CR, and SF on the compressive strength performance were evaluated.

\subsubsection{Splitting tensile strength tests}

The $100 \times 200 \mathrm{~mm}$ cylinder samples were utilized to assess both elasticity modulus and splitting tensile strengths according to ASTM C496 [24] standard. The upper surfaces of the $100 \times 200 \mathrm{~mm}$ samples were capped with sulfur according to ASTM C617 [25] to achieve a smooth surface.

\subsubsection{Flexural tensile strength tests}

The four-point flexural strength tests were carried out on $100 \times 100 \times 500 \mathrm{~mm}$ rubberized SCAAC samples by displacement controlled mode with a rate of $0.02 \mathrm{~mm} / \mathrm{min}$. Three linear variable displacement transducers (LVDT) were utilized to measure the deflections of the specimens. The unnotched beam specimens were selected for the flexural strength tests to observe the influence of steel fiber and tire rubber materials on the crack formation (single crack or multiple cracks), crack types (flexural-shear), and failure mechanism.

\section{Result and discussion}

\subsection{The fresh state properties}

Table 3 gives the fresh state performance of the rubberized SCAAC mixes. The minimum slump flow value for the
SF1TR15 mix was measured as $657 \mathrm{~mm}$, which is above the minimum slump flow values of $550 \mathrm{~mm}$ and $600 \mathrm{~mm}$ according to the EFNARC committee and EN 12350-8 standards [26], respectively. Also, the highest T50 time was obtained as $4 \mathrm{~s}$ on the SF1TR15 SCAAC mix and all T50 values are found to be lower than the maximum suggested T50 flow time of $6 \mathrm{~s}$ with respect to EN 12350-8 standards. The V-Funnel discharge period from the V-Funnel section should be less than $15 \mathrm{~s}$ in order to achieve superior filling ability in accordance with EN 12350-9 standard [27]. The obtained results indicated that V-Funnel discharge time was found to be higher than $16 \mathrm{~s}$, except for SF0CR0TR0 and SF0CR10 specimens. The highest V-funnel discharge duration was obtained as $24.13 \mathrm{~s}$ on the SF1TR15 mix. However; no blocking was observed for all rubberized SCAAC mixes. It should be noted that the SCC test criteria were prepared in accordance with the non-fibrous mixes, and still, there is no guidelines/recommendation exist for the fibrous SCC mixes. The L-Box test represents the passing ability through narrower openings $(41 \pm 1 \mathrm{~mm})$ and EFNARC guideline/specification and EN 12350-10 standards [28] suggest that PL value should be above 0.8 to meet the passing ability criteria. The obtained PL value results revealed that all of the mixes were found to be above 0.8 , indicating adequate passing ability. The fresh state test results pointed out that the rubberized SCAAC mixes have adequate flowability and passing ability performance.

\subsubsection{The influence of RTR and SF on slump flows}

Fig. 2 illustrates the variation of slump flow values with the addition of SF and RTR in the SCAAC mixes. The results pointed out that both RTR and SF inclusions reduced the flowability. The highest slump flow was obtained in the control mix (without rubber and SF), whilst the minimum slump flow was achieved in the specimens with $1 \% \mathrm{SF}$ and $15 \%$ TR (SF1TR15). The slump flows were found to be

Table 3 The fresh state properties of SCGC mixtures

\begin{tabular}{lccc}
\hline Mixture & Flow $(\mathrm{mm})$ & L-Box $(\mathrm{PL})$ & V-Funnel $(\mathrm{s})$ \\
\hline SF0CR0TR0 & $741( \pm 3)$ & $1.00( \pm 0)$ & $10.71( \pm 0.55)$ \\
SF0CR10 & $704( \pm 4)$ & $0.94( \pm 0.01)$ & $14.23( \pm 0.76)$ \\
SF0CR15 & $673( \pm 5)$ & $0.89( \pm 0.02)$ & $17.93( \pm 0.82)$ \\
SF0TR10 & $683( \pm 4)$ & $0.90( \pm 0.01)$ & $19.49( \pm 0.86)$ \\
SF0TR15 & $667( \pm 6)$ & $0.84( \pm 0.02)$ & $22.94( \pm 0.94)$ \\
SF1CR10 & $678( \pm 6)$ & $0.90( \pm 0.02)$ & $17.57( \pm 1.02)$ \\
SF1CR15 & $664( \pm 8)$ & $0.84( \pm 0.03)$ & $19.97( \pm 1.15)$ \\
SF1TR10 & $672( \pm 8)$ & $0.85( \pm 0.02)$ & $3.63( \pm 0.08)$ \\
SF1TR15 & $657( \pm 10)$ & $0.80( \pm 0.03)$ & $3.47( \pm 0.08)$ \\
\hline
\end{tabular}




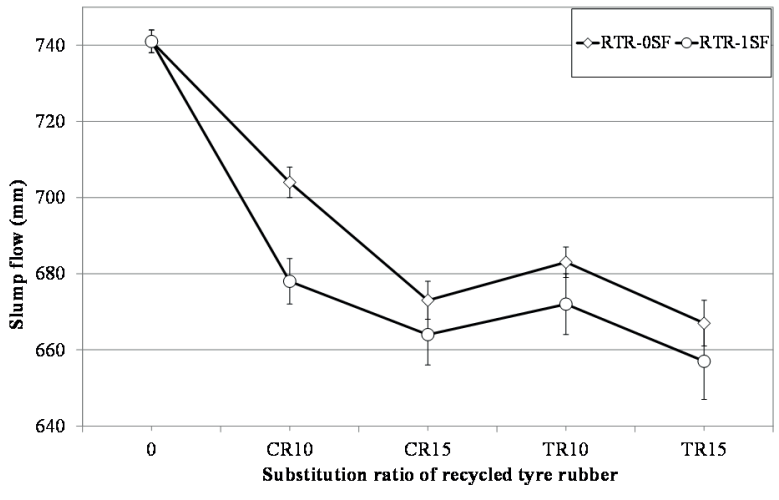

Fig. 2 The effect of SF and RTR on the slump flow values

decreased with an increase in the RTR replacement ratios. The slump flows of the SCAAC mixes including $15 \%$ CR and TR were found less than the mixes including $10 \%$ CR and $10 \%$ TR. A similar result was also obtained in the earlier investigation that the flowability characteristics decreased with an increase in the RTR volume ratio [29].

In addition, the size of the RTR adversely affected the slump flow values. The RTR with bigger sizes (TR) exhibited lower flowability than the RTR with lower sizes (CR). The reduction in the slump flow values was found to be more for the TR incorporated mixes than the CR incorporated mixes under the same replacement ratios as shown in Fig. 1. The inclusion of SF reduced more the slump flow compared to non-fibrous mixtures. The reduction of the slump flow for the $1 \% \mathrm{SF}$ mix was also noted in the earlier studies $[13,17]$.

\subsubsection{The effects of RTR and SF on $T_{50}$ flow duration}

Fig. 3 presents the $T_{50}$ durations for the rubberized SCAAC mixes. The minimum $T_{50}$ flow time was achieved in the samples without RTR and SF (SF0CR0TR0), whilst the maximum T50 flow time was reached in the samples including $15 \%$ TR and $1 \% \mathrm{SF}$. Similar to slump flow results, $\mathrm{T}_{50}$ time increased with increasing RTR and SF volume ratios. Also, the $T_{50}$ flow duration was found more for the TR incorporated mixes than the $\mathrm{CR}$ incorporated mixes under the same replacement ratios.

\subsubsection{The effects of RTR and SF on V-funnel duration}

Fig. 4 presents the V-funnel discharge time of the mixes. The minimum V-funnel discharge duration was achieved in the mixes without RTR and SF, whilst the maximum discharge time was obtained in the mixtures involving $15 \%$ TR and $1 \%$ SF. The V-funnel discharge duration was found to be increased with an increase in the RTR ratio. The TR incorporated mixes showed higher V-funnel flow time than the CR incorporated mixes under the same replacement ratios, indicating that long rubbers decreased the flowability more than short rubbers.

\subsubsection{The effect of RTR and SF on L-box height ratio}

Fig. 5 illustrates the L-Box test results for the rubberized SCAAC mixtures. For the required passing ability characteristics, the PL value should be above 0.8 according to the related guidelines/standards. The results showed that the PL values of all mixes were above the minimum PL value of 0.8. Similar to other tested fresh state properties,

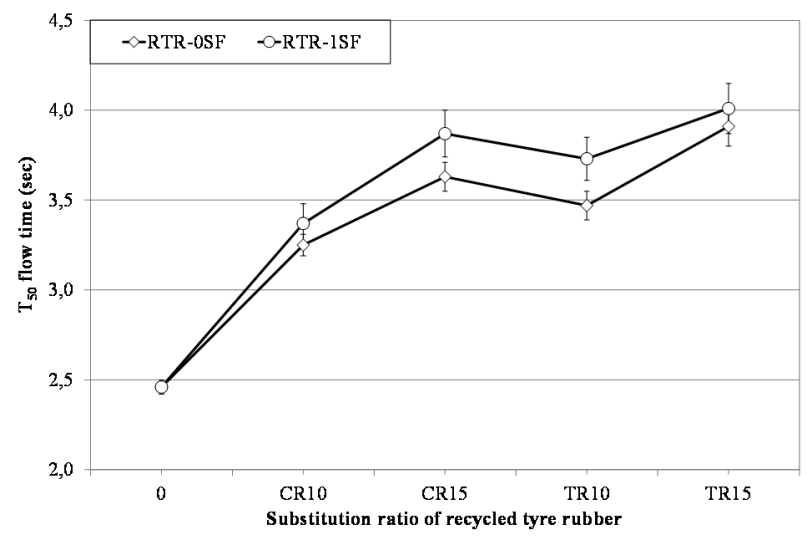

Fig. 3 The effect of RTR and SF on the T50 flow duration

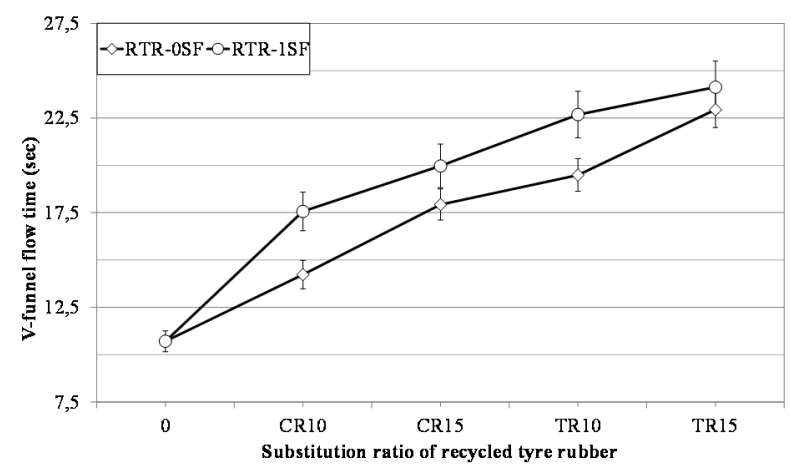

Fig. 4 The effect of SF and recycled rubber on V-funnel time

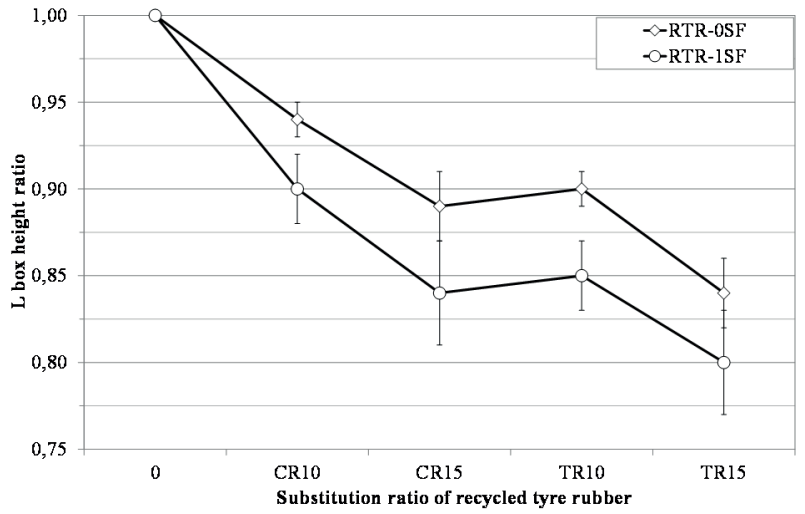

Fig. 5 The effect of SF and RTR on the L-Box height ratio 
PL value decreased with an increasing RTR ratio and SF inclusion. Also, CR incorporated mixes exhibited higher PL values than the TR incorporated mixes for the same replacement ratios. The fresh state results indicated that RTR decreased the fresh state properties, and the reduction was found more with the SF inclusions. Also, TR reduced the fresh state performances more than the $\mathrm{CR}$.

\subsection{Hardened state properties of rubberized specimens}

Table 4 presents the hardened state test results of the rubberized SCAAC specimens. The results indicated that compressive strength, modulus of elasticity, splitting tensile strength, and flexural strength decreased with an increase in RTR substitution ratios for the specimens without SF. The reduction in mechanical strength due to the RTR substitution ratio was also reported in previous research [30, 31]. The loss of strength may be attributed to the loss of bonding between the RTR and matrix, loss of stiffness due to inclusions of RTR, and reduced density with an increase in the RTR substitutions. However, the deformation capacity significantly enhanced with RTR utilization when $1 \%$ SF was utilized. The inclusion of SF slightly decreased the compressive strength, while the modulus of elasticity, splitting tensile strength, and flexural strength slightly enhanced with the addition of SF. Meanwhile, deformation and energy absorption capacities of specimens significantly improved when SF and RTR were utilized together.

\subsubsection{Compressive strength}

Fig. 6 indicates the compressive strength results of the rubberized SCAAC specimens. The RTR utilization decreased the compressive strength results, and the compressive strength decrease increased with an increase in the RTR ratios. A slight compressive strength enhancement was observed with the $1 \%$ SF inclusions. The results

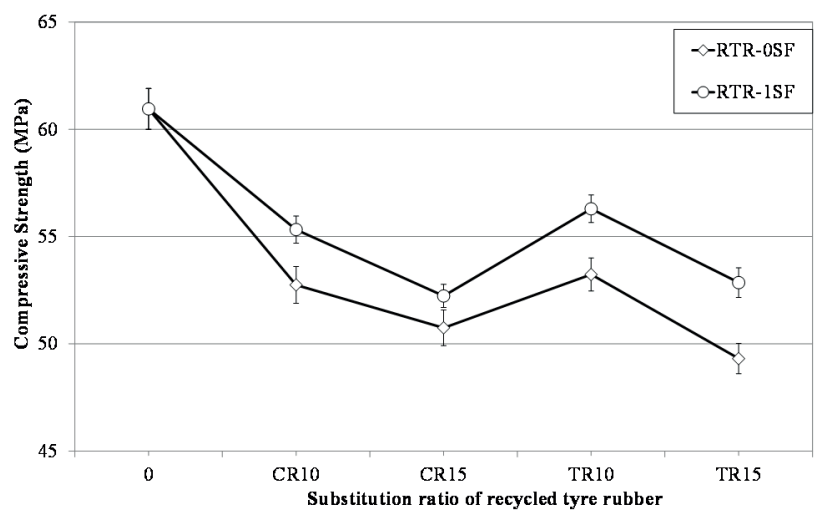

Fig. 6 The effect of RTR and SF on the compressive strengths

also showed that the compressive strength was found independent from the rubber sizes since similar compressive strength values were obtained in the TR and CR specimens under the same replacement ratios. Meanwhile, the compressive strength improvement due to the $1 \%$ SF addition was also reported in the earlier investigations $[13,17]$. In addition, significant compressive strength improvement was also reported due to the SF inclusion for the fly ash based geopolymer SCC [32]. This compressive strength improvement may be attributed to the improved SF and matrix bond strength caused by the crack arresting capability of fibers [32].

\subsubsection{Splitting tensile strength}

Fig. 7 indicates the splitting tensile strength results of the specimens. The results indicated that the splitting tensile strength of the non-fibrous specimens slightly decreased with the RTR inclusions. However, SF inclusion significantly enhanced the splitting tensile strength of the rubberized SCAAC specimens. For the non-fibrous specimens, the average splitting tensile strength decrease for the $10 \%$ and $15 \%$ RTR substitutions were $8 \%$ and $12 \%$, whilst the average splitting tensile strength improvements

Table 4 Hardened state properties of rubberized SCAAC specimens

\begin{tabular}{lccc}
\hline Specimens & $\begin{array}{c}\text { Compressive Strength } \\
(\mathrm{MPa})\end{array}$ & $\begin{array}{c}\text { Modulus of Elasticity } \\
(\mathrm{GPa})\end{array}$ & $\begin{array}{c}\text { Splitting Tensile Strength } \\
(\mathrm{MPa})\end{array}$ \\
\hline SF0CR0TR0 & $60.95( \pm 0.95)$ & $20.73( \pm 0.79)$ & $\begin{array}{c}\text { Flexural Strength } \\
(\mathrm{MPa})\end{array}$ \\
SF0CR10 & $52.74( \pm 0.86)$ & $19.17( \pm 0.67)$ & $3.43( \pm 0.54)$ \\
SF0CR15 & $50.74( \pm 0.83)$ & $18.47( \pm 0.68)$ & $3.17( \pm 0.45)$ \\
SF0TR10 & $53.23( \pm 0.77)$ & $19.52( \pm 0.61)$ & $2.97( \pm 0.46)$ \\
SF0TR15 & $49.31( \pm 0.71)$ & $19.18( \pm 0.57)$ & $3.12( \pm 0.38)$ \\
SF1CR10 & $55.32( \pm 0.63)$ & $21.97( \pm 0.54)$ & $3.02( \pm 0.44)$ \\
SF1CR15 & $52.23( \pm 0.54)$ & $22.87( \pm 0.49)$ & $3.95( \pm 0.41)$ \\
SF1TR10 & $56.29( \pm 0.64)$ & $22.26( \pm 0.43)$ & $4.61( \pm 0.41)$ \\
SF1TR15 & $52.85( \pm 0.69)$ & $23.19( \pm 0.52)$ & $4.49( \pm 0.39)$ \\
\hline
\end{tabular}




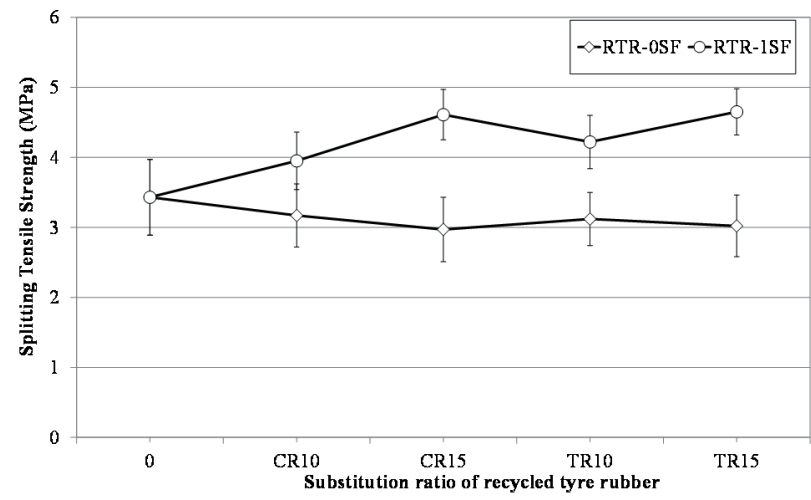

Fig. 7 The effect of RTR and SF on the splitting tensile strength

of the steel fibrous specimens were $19 \%$ and $35 \%$ for the $10 \%$ and $15 \%$ RTR substitutions for SF0CR0TR0 specimens. The SF inclusions to the rubberized SCAAC specimens enhanced the splitting tensile strength, and the improvement was found to be increased further with the higher RTR replacements $(15 \%)$. The results also pointed out that similar splitting tensile strength values were obtained in the specimens with $\mathrm{CR}$ and TR under the same replacement ratios. However, in literature, there is a conflict about the effect of rubber size on mechanical strengths. Some studies reported that specimens with finer rubbers showed higher mechanical strengths [31, 33], while others stated that specimens with coarse rubbers performed higher mechanical strengths $[34,35]$. In this research, similar mechanical strengths were obtained for the specimens with coarse and fine rubbers.

\subsubsection{Flexural strength}

Table 4 gives the flexural strength test results of the rubberized SCAAC specimens under four-point loading. The results indicated that the flexural strength of the non-fibrous specimens slightly decreased with the RTR replacements. For the non-fibrous specimens, the average flexural strength decrease for the $10 \%$ and $15 \%$ RTR replacements were $8 \%$ and $12 \%$. However, the flexural strength of the steel fibrous specimens slightly improved with the RTR replacements. The average flexural strength enhancements were $5 \%$ and $6 \%$ for the $10 \%$ and $15 \%$ RTR replacements with respect to SF0CR0TR0 specimens. The splitting tensile and flexural strength improvements due to the SF incorporations were also stated in the earlier investigations $[17,32]$. This improvement may be due to the hydrophilic nature of SF [36], improving the bond between SF and matrix. Also, high elastic modulus of SF facilitates stress distribution so that tensile crack formation is restrained, improving the mechanical strengths [37].
Fig. 8 shows the load versus displacement curves of the specimens under four-point loading. A linear slope was obtained up to the initiation of the first crack and then stress-softening was observed in the post-peak regions. The non-fibrous specimens showed very low deformation capacities, whilst SF rubberized specimens exhibited very high deformation capacities and toughness as shown in Fig. 8(a) and Fig. 8(b), respectively. The superior deformation capacity was obtained in the SF1TR15 rubberized specimens, while the minimum deformation capacity was reached in the SF1CR10 rubberized specimens. A similar result was also obtained in the previous investigation that the peak strain decreased as the crumb rubber size reduced [38]. The high ductility of the specimens is mainly attributed to the crack bridging ability of the SF [24, 39].

\subsection{Failure modes of the flexural specimens}

Fig. 9 illustrates the cracking patterns of the rubberized SCAAC specimens under four-point loading. The flexure type of cracks and flexural failure realized in all specimens. For the non-fibrous rubberized specimens, a big main crack was observed on the bending zone (Figs. 9(a), 9(c) and 9(d)), except for SF0CR15 specimens (Fig. 9(b)).

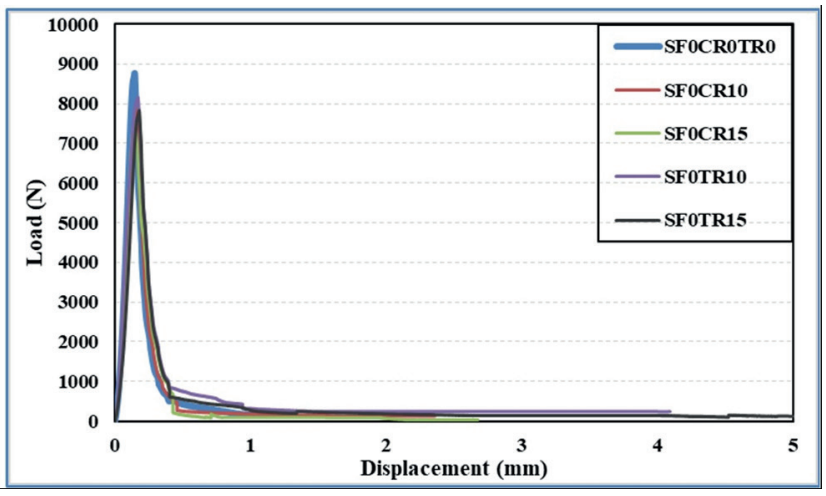

(a)

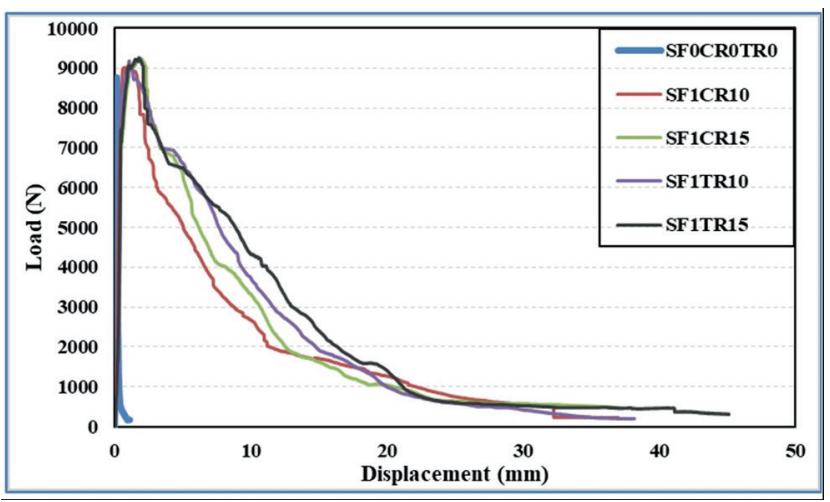

(b)

Fig. 8 Load vs displacement curves of the rubberized SCAAC specimens 
For the SF0CR15 specimens, very small hairline crack $(\leq 0.1 \mathrm{~mm})$ was observed as well as the main flexural type of crack. For the steel fibrous rubberized specimens, multiple cracks, shown as red circles in Figs. 9(e)-(h), were observed in the bending zone. The obtained cracks pointed out that stress transfers were available amongst the SF due to the crack arresting capability of the hooked-end $\mathrm{SF}$, resulting in enhanced deformation capacity. When the obtained cracks were investigated in details, one main flexural crack was observed on the $10 \%$ CR replaced (SF1CR10) steel fibrous specimens at the tension zone, and branching of this crack occurred at the compression region, Fig. 9(e). For the $15 \%$ CR including (SF1CR15) steel fibrous specimens, one main crack and two small hairline cracks were obtained and the cracks reached to the main crack in the tension zone. The main flexural crack proceeded to the compression zone with branching and resulted in the failure, Fig. 9(f). For the $10 \%$ TR replaced (SF1TR10) steel fibrous specimens, two vertical hairline cracks were observed, and these two cracks were found independent from the main crack and proceeded to the half of the specimen. The main flexural crack with branching in both tension and compression regions proceeded to the failure, Fig. 9(g). For the $15 \%$ TR replaced steel fibrous (SF1TR15) specimens, the main crack with a wider size in the tension zone was observed and proceeded to the failure. However, additional two vertical cracks were also observed, and one of them had a wider crack width $(>0.1 \mathrm{~mm})$ with branching in the tension zone, Fig. 9(h). These branched secondary cracks caused more deformation, which is an indicator of the highest load and deformation capacity in the SF1TR15 specimens under flexure.

\subsection{Scanning Electron Microscopy (SEM) analysis}

Fig. 10 shows the scanning electron microscopy (SEM) of the rubberized SCAAC specimens. The SEM results indicated that continuous geopolymer gel in the slag based AAC showed more compact and homogeneous morphologies. Also, cavities and angular slag particles were barely found. The well-distributed paste with less unreacted slag grains, indicating denser, homogeneous, and less porous microstructure, resulting in higher mechanical strength for the SCAAC specimens. However, wider interconnected macro-cracks were observed in the microstructure, which can be attributed to the water evaporation and self-desiccation [39], and shrinkage of the reaction products [40]. This may be caused by the improper bond between matrix and rubber particles, which may result in a reduction in the mechanical strength of the specimens.

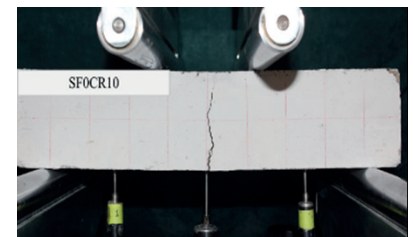

(a)

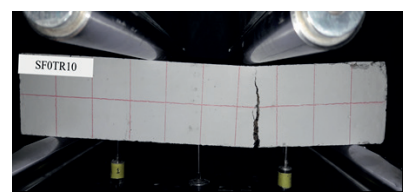

(c)

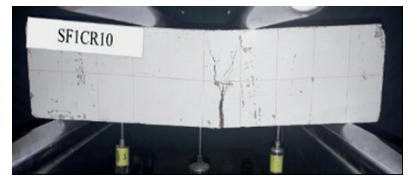

(e)

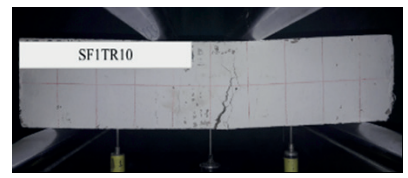

(g)

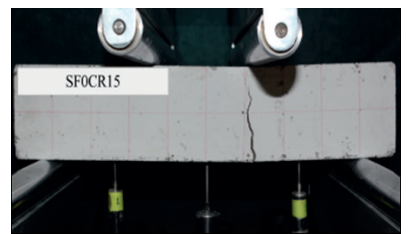

(b)

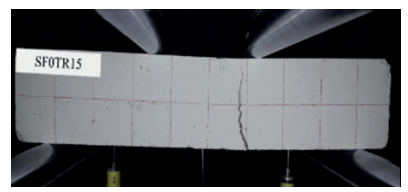

(d)

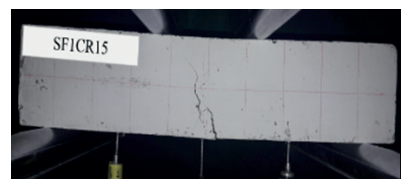

(f)

(h)

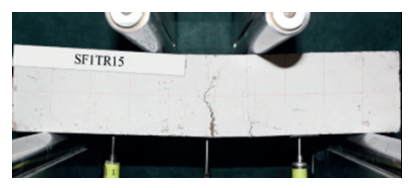

Fig. 9 Failure shapes of the rubberized SCAAC specimens

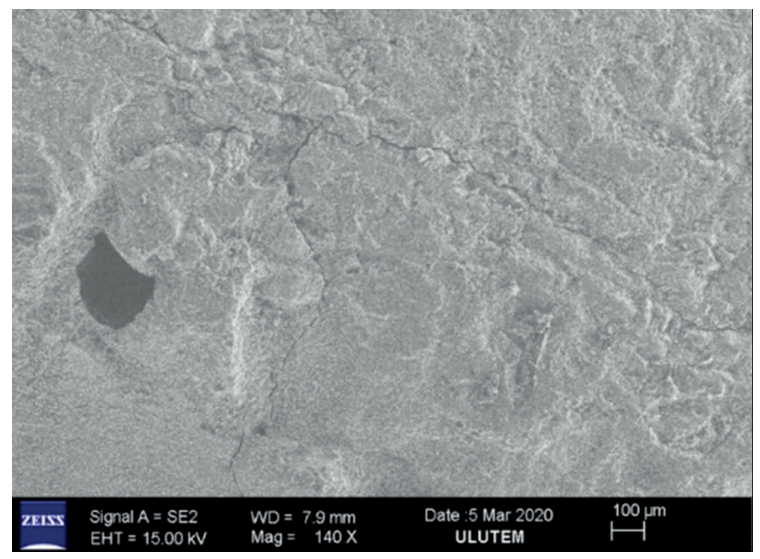

(a)

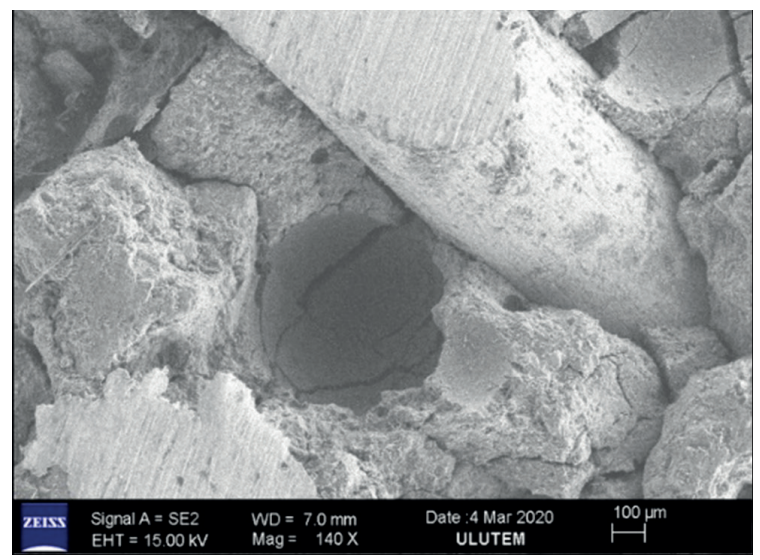

(b)

Fig. 10 SEM images of rubberized SCAAC specimens 


\section{Conclusions}

In this research, the fresh and hardened state performance of rubberized self-compacting alkali activated concrete (SCAAC) specimens with/out steel fibers (SF) were investigated. The crumb rubbers (CR) and tire rubber chips (TR) were used as a substitution to natural aggregates with $10 \%$ and $15 \%$. The SF with a fiber volume of $1 \%$ was also used to investigate the possible utilization for structural applications. The following results were obtained:

The flowability and passing ability of the mixes decreased with an increase in the RTR content and rubber particle size. Among the RTR, the TR adversely influenced the fresh state performance more than the CR.

The specimens with $1 \%$ SF and $15 \%$ TR performed the lowest fresh state performance; however, all mixes had adequate flowability and passing ability based on the related guidelines and standards.

The mechanical strengths of the specimens were found to be independent of the rubber sizes since similar mechanical strengths were obtained for the specimens with TR and CR.

\section{References}

[1] Day, K. E., Holtze, K. E., Metcalfe-Smith, J. L., Bishop, C. T., Dutka, B. J. "Toxicity of leachate from automobile tires to aquatic biota", Chemosphere, 27(4), pp. 665-675, 1993.

https://doi.org/10.1016/0045-6535(93)90100-J

[2] Chen, S.-J., Su, H.-B., Chang, J.-E., Lee, W.-J., Huang, K.-L., Hsieh, L.-T., Huang Y.-C., Lin W.-Y., Lin, C.-C. "Emissions of polycyclic aromatic hydrocarbons (PAHs) from the pyrolysis of scrap tires", Atmospheric Environment, 41(6), pp. 1209-1220, 2007.

https://doi.org/10.1016/j.atmosenv.2006.09.041

[3] Pacheco-Torgal, F., Ding, Y., Jalali, S. "Properties and durability of concrete containing polymeric wastes (tyre rubber and polyethylene terephthalate bottles): An overview", Construction and Building Materials, 30, pp. 714-724, 2012.

https://doi.org/10.1016/j.conbuildmat.2011.11.047

[4] Wang, Q.-Z., Wang, N.-N., Tseng, M.-L., Huang, Y.-M., Li, N.-L. "Waste tire recycling assessment: Road application potential and carbon emissions reduction analysis of crumb rubber modified asphalt in China", Journal of Cleaner Production, 249, Article No. 119411, 2020.

https://doi.org/10.1016/j.jclepro.2019.119411

[5] Chan, C. W., Yu, T., Zhang, S. S., Xu, Q. F. "Compressive behaviour of FRP-confined rubber concrete", Construction and Building Materials, 211, pp. 416-426, 2019.

https://doi.org/10.1016/j.conbuildmat.2019.03.211

[6] Liu, F., Chen, G., Li, L., Guo, Y. "Study of impact performance of rubber reinforced concrete", Construction and Building Materials, 36, pp. 604-616, 2012.

https://doi.org/10.1016/j.conbuildmat.2012.06.014
The very high deformation capacities were obtained due to the inclusion of $1 \% \mathrm{SF}$. The post-peak performance enhanced with higher RTR ratios and the bigger TR particles performed slightly higher deformation capacity than the short CR particles when $1 \%$ SF were utilized.

The failure modes indicated that one main flexural crack was obtained for the non-fibrous specimens, while more and wider cracks were observed on the specimens including $1 \%$ SF and $15 \%$ RTR, resulting in higher post-peak performance.

The SEM results revealed that denser and homogeneous microstructure was obtained in the specimens. However, wider interconnected macrocracks were observed in the microstructure, probably due to the water evaporation, self-desiccation, and shrinkage of the reaction products.

The SF reinforced rubberized specimens should be used in structural applications, particularly in seismic zones.

\section{Acknowledgement}

This work was supported by Gaziantep University Scientific Research Projects Coordination Unit. Project number: MF.DT.17.06.

[7] Gholampour, A., Ozbakkaloglu, T., Hassanli, R. "Behavior of rubberized concrete under active confinement", Construction and Building Materials, 138, pp. 372-382, 2017. https://doi.org/10.1016/j.conbuildmat.2017.01.105

[8] Aslani, F., Ma, G., Wan, D. L. Y., Le, V. X. T. "Experimental investigation into rubber granules and their effects on the fresh and hardened properties of self-compacting concrete", Journal of Cleaner Production, 172, pp. 1835-1847, 2018. https://doi.org/10.1016/j.jclepro.2017.12.003

[9] Nazari, A., Sanjayan, J. G. "Modelling of compressive strength of geopolymer paste, mortar and concrete by optimized support vector machine", Ceramics International, 41(9B), pp. 12164-12177, 2015. https://doi.org/10.1016/j.ceramint.2015.06.037

[10] Çevik, A., Alzeebaree, R., Humur, G., Niş, A., Gülşan, M. E. "Effect of nano-silica on the chemical durability and mechanical performance of fly ash based geopolymer concrete", Ceramics International, 44(11), pp. 12253-12264, 2018. https://doi.org/10.1016/j.ceramint.2018.04.009

[11] Alzeebaree, R., Gulsan, M. E., Nis, A., Mohammedameen, A., Cevik, A. "Performance of FRP confined and unconfined geopolymer concrete exposed to sulfate attacks", Steel and Composite Structures, 29(2), pp. 201-218, 2018. https://doi.org/10.12989/scs.2018.29.2.201

[12] Alzeebaree, R., Çevik, A., Mohammedameen, A., Niş, A., Gülşan, M. E. "Mechanical performance of FRP-confined geopolymer concrete under seawater attack", Advances in Structural Engineering, 23(6), pp. 1055-1073, 2019. https://doi.org/10.1177/1369433219886964 
[13] Niş, A. "Mechanical Properties of Steel Fiber Reinforced SelfCompacting Concrete", International Journal of Engineering Technologies, 4(1), pp. 33-40, 2018. [online] Available at: https:// hdl.handle.net/11363/564

[14] Zhang, P., Zheng, Y., Wang, K., Zhang, J. "A review on properties of fresh and hardened geopolymer mortar", Composites Part B: Engineering, 152, pp. 79-95, 2018. https://doi.org/10.1016/j.compositesb.2018.06.031

[15] Huseien, G. F., Sam, A. R. M., Alyousef, R. "Texture, morphology and strength performance of self-compacting alkali-activated concrete: Role of fly ash as GBFS replacement", Construction and Building Materials, 270, Article No. 121368, 2021. https://doi.org/10.1016/j.conbuildmat.2020.121368

[16] Huseien, G. F., Shah, K. W. "Durability and life cycle evaluation of self-compacting concrete containing fly ash as GBFS replacement with alkali activation", Construction and Building Materials, 235, Article No. 117458, 2020. https://doi.org/10.1016/j.conbuildmat.2019.117458

[17] Niş, A., Özyurt, N., Özturan, T. "Variation of Flexural Performance Parameters Depending on Specimen Size and Fiber Properties", Journal of Materials in Civil Engineering, 32(4), Article No. 04020054, 2020 . https://doi.org/10.1061/(ASCE)MT.1943-5533.0003105

[18] di Prisco, M., Felicetti, R., Iorio, F., Gettu, R. "On the identification of SFRC tensile constitutive behaviour", In: de Borst, R., Mazars, J., Pijaudier-Cabot, G., van Mier, J. G.-M. (eds.) Fracture Mechanics of Concrete Structures, A.A. Balkema Publishers, Rotterdam, Netherlands, 2001, pp. 541-548. [online] Available at: http://citeseerx.ist.psu.edu/viewdoc/download?doi= 10.1.1.1089.5457\&rep=rep1\&type $=$ pdf

[19] ASTM "ASTM C136 / C136M - 19 Standard Test Method for Sieve Analysis of Fine and Coarse Aggregates", ASTM International, West Conshohocken, PA, USA, 2019. https://doi.org/10.1520/C0136_C0136M-19

[20] Memon, F. A., Nuruddin, M. F., Khan, S., Shafiq, N., Ayub, T. "Effect of sodium hydroxide concentration on fresh properties and compressive strength of self-compacting geopolymer concrete", Journal of Engineering Science and Technology, 8(1), pp. 44-56, 2013. [online] Available at: https://core.ac.uk/download/pdf/26994501.pdf

[21] Olivia, M., Nikraz, H. "Properties of fly ash geopolymer concrete designed by Taguchi method", Materials and Design, 36, pp. 191198, 2012. https://doi.org/10.1016/j.matdes.2011.10.036

[22] Niş, A., Altındal, İ. "Compressive Strength Performance of Alkali Activated Concretes under Different Curing Conditions", Periodica Polytechnica Civil Engineering, 65(2), pp. 556-565, 2021. https://doi.org/10.3311/PPci.17016

[23] ASTM "ASTM C39 / C39M - 21 Standard Test Method for Compressive Strength of Cylindrical Concrete Specimens", ASTM International, West Conshohocken, PA, USA, 2021. https://doi.org/10.1520/C0039_C0039M-21

[24] ASTM "ASTM C496 / C496M - 17 Standard Test Method for Splitting Tensile Strength of Cylindrical Concrete Specimens", ASTM International, West Conshohocken, PA, USA, 2017. https://doi.org/10.1520/C0496_C0496M-17
[25] ASTM "ASTM C617 / C617M - 15 Standard Practice for Capping Cylindrical Concrete Specimens", ASTM International, West Conshohocken, PA, USA, 2015. https://doi.org/10.1520/C0617 C0617M-15

[26] CEN "EN 12350-8:2019 Testing fresh concrete - Part 8: Selfcompacting concrete - Slump-flow test", European Committee for Standardization, Brussels, Belgium, 2019.

[27] CEN "EN 12350-9:2010 Testing fresh concrete - Part 10: Selfcompacting concrete - V-funnel test", European Committee for Standardization, Brussels, Belgium, 2010.

[28] CEN "EN 12350-10:2010 Testing fresh concrete - Part 10: Selfcompacting concrete - L box test", European Committee for Standardization, Brussels, Belgium, 2010.

[29] Ismail, M. K., Hassan, A. A. A. "Use of metakaolin on enhancing the mechanical properties of self-consolidating concrete containing high percentages of crumb rubber", Journal of Cleaner Production, 125, pp. 282-295, 2016. https://doi.org/10.1016/j.jclepro.2016.03.044

[30] Atahan, A. O., Yücel, A. Ö. "Crumb rubber in concrete: Static and dynamic evaluation", Construction and Building Materials, 36, pp. 617-622, 2012. https://doi.org/10.1016/j.conbuildmat.2012.04.068

[31] Su, H., Yang, J., Ling, T.-C., Ghataora, G. S., Dirar, S. "Properties of concrete prepared with waste tyre rubber particles of uniform and varying sizes", Journal of Cleaner Production, 91, pp. 288-296, 2015.

https://doi.org/10.1016/j.jclepro.2014.12.022

[32] Gülşan, M. E., Alzeebaree, R., Rasheed, A. A., Niş, A., Kurtoğlu, A. E. "Development of fly ash/slag based self-compacting geopolymer concrete using nano-silica and steel fiber", Construction and Building Materials, 211, pp. 271-283, 2019. https://doi.org/10.1016/j.conbuildmat.2019.03.228

[33] Jafari, K., Toufigh, V. "Experimental and analytical evaluation of rubberized polymer concrete", Construction and Building Materials, 155, pp. 495-510, 2017. https://doi.org/10.1016/j.conbuildmat.2017.08.097

[34] Albano, C., Camacho, N., Reyes, J., Feliu, J. L., Hernández, M. "Influence of scrap rubber addition to Portland I concrete composites: Destructive and non-destructive testing", Composite Structures, 71(3-4), pp. 439-446, 2005. https://doi.org/10.1016/j.compstruct.2005.09.037

[35] Skripkiūnas, G., Grinys, A., Miškinis, K. "Damping Properties of Concrete with Rubber Waste Additives", Materials Science (Medžiagotyra), 15(3), pp. 266-272, 2009. [online] Available at: https://www.researchgate.net/publication/228476271_Damping_ Properties_of_Concrete_with_Rubber_Waste_Additives

[36] Ranjbar, N., Talebian, S., Mehrali, M., Kuenzel, C., Metselaar, H. S. C., Jumaat, M. Z. "Mechanisms of interfacial bond in steel and polypropylene fiber reinforced geopolymer composites", Composites Science and Technology, 122, pp. 73-81, 2016. https://doi.org/10.1016/j.compscitech.2015.11.009

[37] Zhong, H., Poon, E. W., Chen, K., Zhang, M. "Engineering properties of crumb rubber alkali-activated mortar reinforced with recycled steel fibres", Journal of Cleaner Production, 238, Article No. 117950, 2019. https://doi.org/10.1016/j.jclepro.2019.117950 
[38] Ren, R., Liang, J.-F., Liu, D.-W., Gao, J.-H., Chen, L. "Mechanical behavior of crumb rubber concrete under axial compression", Advances in Concrete Construction, 9(3), pp. 249-256, 2020. https://doi.org/10.12989/acc.2020.9.3.249

[39] Wardhono, A., Gunasekara, C., Law, D. W., Setunge, S. "Comparison of long term performance between alkali activated slag and fly ash geopolymer concretes", Construction and Building Materials, 143, pp. 272-279, 2017.

https://doi.org/10.1016/j.conbuildmat.2017.03.153
[40] Lee, N. K., Jang, J. G., Lee, H. K. "Shrinkage characteristics of alkali-activated fly ash/slag paste and mortar at early ages", Cement and Concrete Composites, 53, pp. 239-248, 2014.

https://doi.org/10.1016/j.cemconcomp.2014.07.007 